given me opportunities of using it more than ordinary in surgical cases. I have not administered it internally, but from what you state I shall certainly take the earliest opportunity of giving it a trial.

It has been very often used after the application of leeches, where there was difficulty of stopping the oozing of blood, and uniformly with the most decided success. One of these cases was that of our housesurgeon, who had fever, and being a young, stout, and florid person, with early symptoms of head affection, leeches were ordered, which, by his own desire, were applied inside of both nostrils; the bites bled profusely, and there was a difficulty in stopping the bleeding. Cold applications to the head, and plugging the nostrils, \&c., were tried without effect, when the " maticò," in leaf, was applied over the bites, and pressed on with the point of the finger; the remedy proved immediately successful. This is, in my opinion, a good and decided case, happening in the person of an intelligent and experienced medical man. $\mathrm{He}$ describes the feeling produced by the leaf to be, one of increased heat and throbbing, which continued for about five minutes, when all unpleasant sensation went off; others to whom it was applied described their feelings as very similar to those just mentioned. The maticò was also applied to a man brought into this hospital with a wound of the right temple; a considerable branch of the temporal artery had been divided; the wound was dressed, and a compress and bandage applied, but still the blood burst out; cold water was several times had recourse to, still the bleeding returned after a while; at last the matico was used; at first I stuffed the wound with the powder, but found it not to answer so well as the leaf, being soon washed away from the wound in the vessel; I then pressed in scveral pieces of the leaves, holding them firmly for some time with the point of the finger; the result was, that we had no more hæmorrhage. We had a somewhat similar case of a man with a wound of a branch of the palmar artery, which resisted graduated compression and bandages; and in which the maticò was used with the best success.

From these cases I cannot doubt but that the matico has most decided styptic qualities, and that it may become a very valuable addition to our materia medica. It will afford me pleasure if I can give you any farther testimony of the effects of this substance, in which you seem to feel a peculiar interest ; I shall persevere in trying it in cases where I think it appropriate, whether medical or surgical.

Mr. Crichton, my successor for the following year in the infirmary, has promised to follow up the experiments with the matico, and the house surgeon takes an interest in the matter, so that $I$ hope to give you further proof of its good effects as a styptic.

I am, dear Sir, Yours faithfully, Wm. Monro."

P.S. I avail myself of this opportunity of recording that my friend, Dr. Kendrick, of Warrington, informed me that he had occasion to apply it to a divided artery in a gentleman who cut his throat, and that it instantly stayed the effusion of blood, which was taking place with cunsiderable violence.
ON THE

\section{RADICAL CURE OF HERNIA;}

THE SUBSTANCE OF A PAPEK READ BEFORE THE HARVEIAN SOCIETY.

By l'. BFNNETT LUCAS, Esq.,

Senior Surgeon to the Metropolitan Free Hospital, and Lec turer on Anatomy and Physiology at the Westminster Hospital School of Medicine.

The possibility of a radical cure of hernia is admitted by all authors who have written upon this disease, and is acquiesced in by all reflecting and practical surgeons.

Universal as this assent is, it is no less true that out of the immense number of patients afflicted with hernia, who are daily to be met with at our public hospitals, or who present themselves to us in private practice, but a small number holds out to the surgeon a reasonable hope of a perfect recovery by any method of treatment he may adopt.

It has been ascertained, by statistical reports, that about one-sixteenth of the human race is afflicted with hernia. This fact has been arrived at from the reports of the London Truss Society, and from similar institutions; and it is much to be regretted that a more lengthened detail of the cases has not been furnished. It is only by a fair, unprejudiced view of a large number of cases, each individually describedthe history of each given - the cause or causes which predisposed to the disease, and which also excited it - the length of time the hernia existed before the patient applied for relief-the condition of the abdominal parieties and their contents-added to the usual inquiries of the age, the sex, and the occupation of the patient-the kind of hernia, and its facility of reduction-it is only by such essential considerations as these that we can select one case from another, with a view to effect its radical cure.

Some years since I was introduced to a medical gentleman, who arrived in this country from America, furnished with numerous testimonials from Professor Pattison and others, in support of his pretensions to cure hernia by the application of trusses. I witnessed some cases in which he ccrtainly succeeded, and others which received no benefit from the means he cmployed. I was, however, so fully satisfied of the utility of his plan of proceeding, and that it was founded upon correct views of the animal economy, that I did not hesitate to apply a similar method of treatment to two cases of oblique inguinal hernia.

The subjects of both these cases were young men, one aged twenty-six years, the other thirty years. In the elder of the two the treatment failed, but was productive of no bad consequences. The case of the younger forms the subject of this paper.

Mr. A. B., aged twenty-six years, was vaulting into his saddle, when he felt a slight and sudden pain in his right groin, which extended down the outer side of his leg, and was accompanied with the sensation of something having given way. These feelings subsided in a few minutes, and he continued his ride as usual. On his return home he observed a small tumour in his groin, which he considered of so little moment that he continued his daily avocations for a month, and these were the cuntrary of inactive, before he T. J. applied to me. 
When he was made acquainted with the nature of his disorder, he suffered great mental anxiety from the apparent lopelessness of his ever being cured; and being a young man of some property, and an attractive person, and unmarried, he felt the necessity of wearing a truss, with as uneasy a mind as he did the danger which hourly attended his not doing so. At this time the tumour, which was a well-marked oblique inguinal hernia, protruded at the external or anterior abdominal aperture for more than an inch, and was reduced with the utmost facility. It was an enterocele.

A truss of ordinary construction was applied in the usual manmer, and at the end of a year the hernia was still present, protruding as usual when the truss was removed, and when the patient made any respiratoly effort.

In this condition of affairs, it was proposed to endeavour to effect, by pressure, a consolidation of the tissues in the immediate ricinity of the posterior inguinal aperture, and thus to present a barrier to the protrusion of intestine. To the accomplishing of this end a truss was applied, which presented these peculiarities:-Its spring was powerfully strong, and its pad, or rather, what corresponded to this piece of the ordinary instrument, was made of box-wood, and was conical, but blunted at its apex. The hernia was reduced; a silk handkerchief, folded three or four turns, was applied over the posterior abdominal aperture, and, with the handkerchief intervening, the truss was applied, its wedge being accurately fitted to the opening.

The curve of the trusis did not consist of a single solid arc of steel, but of several plates of this metal, so that the amount of pressure could be regulated according to the feelings of the patient, by the removal of one or more of these springs.

This instrument the patient wore day and night for two months. At first he experienced some inconvenience from the firm pressure against the abdominal wall, and two of the steel curves were removed; after wearing the instrument in this degree of force for a few days, the removed arcs of steel were replaced, and at the end of six weeks the hernia ceased to descend.

A truss of ordinary construction, exerting little pressure, but rather support, and with a soft, flattened pad, was worn by the patient for some months. I hear occasionally from him; he tells me that he has left off his truss for more than a year, is married, and remains free from the disease.

The exciting cause of the hernia in this patient I have already mentioned; that which predisposed to it is, perhaps, more interesting. The patient had typhus fever, and recovered, after a long and tedious confinement, greatly emaciated. As so frequently occurs after recovery from prolonged functional disturbance, he rapidly increased in bulk, and continued for some months in a most unusual state of obesity. In this condition he used more than ordinary exercise, and was gradually approaching his healthy standard when the hernia made its appearance, from the exertion I have mentioned.

I shall not trouble the society with the narration of other cases. I have nutes of five others in which I have adopted a similar proceeding. In two of these
I have every confidence of a similar happy result. They are cases of single oblique inguinal hernia, confined to the right side in each. There is still an impulse given at the posterior abdominal aperiure, but no protrusion.

In one case I succeeded in blocking up the posterior abdominal aperture; but, unfortunately, a direct intestinal hernia made its appearance on the same side, the result, I have no hesitation in stating, of the closure of the opening in the transversalis fascia.

Mr. Guthrie and myself saw this patient together two years ago. At first we thought that the two rings had approached each other, and those changes in the abdominal apertures and inguinal canal had taken place, which are known to occur in old oblique hernix. That this was not the case, however, was satisfactorily ascertained by the following manipulation :-I inscrted my index finger along the spermatic chord to the posterior abdominal ring, and there its further progress was firmly impeded; by then altering the oblique position of my hand, I made lirect pressure against the posterior ring, so as to prevent the possibility of a descent; and upon now making the patient cough, the hernia descended between my hand and the pubes, directly through the anterior ring.

To most of my hearers it may not appear to be a very novel proposal to cure herniæ by the application of trusses. But I believe none will deny that these instruments have been directed to the palliation of symptoms, and security against strangulation, rather than to the accomplishing of a permanent cure.

Whatever opinion may be entertained of the merits or demerits of thus dealing with hernix, it camnot be too forcibly insisted upon that the circumstances attending very many cases of the disease prohibit the surgeon from attempting a radical cure. Where the predisposing causes to the affection are still in operation, it would be idle to attempt it, without previously attempting their removal. Herniæ of long standing offer many serious impediments to the adoption of the measure proposed; and in the old subject the reparative powers are so feeble that little in this case can be expected. In the young subject, and more especially where the hernia was occasioned by a violent exertion, I should expect the happiest results.

There is another question of some moment which is involved in the consideration of the cure of hernie, and this relates to the insurance of lives.

In an interview I had, a few months ago, with the surgeon of an extensive life assurance company, the question of the cure of hernia was stated; and this gentleman said, that under no circuinstances would the company insure the life of a patient who had at any time been the subject of hernia.

\section{SMALL HOSPITALS.}

There are only fifteen beds in the hospital at Goettingen, and I do not wish for more. I do not think that the experienced practitioner is formed by the number of patients. Experience is the result not of secing merely, but of reflecting. It is not eating, but digestion, that gives strength - Richter's Medical Observations.-I. D. J. 